\title{
Pyrolysis of Wood Residues in a Cylindrical Batch Reactor: Effect of Operating Parameters on the Quality and Yield of Products
}

\author{
R. Kizza ${ }^{1}$, N. Banadda ${ }^{1,2}$, I. Kabenge ${ }^{1}$, J. Seay ${ }^{3}$, S. Willet $^{3}$, N. Kiggundu ${ }^{1} \&$ A. Zziwa ${ }^{1}$ \\ ${ }^{1}$ Department of Agricultural and Bio-Systems Engineering, Makerere University, Kampala, Uganda \\ ${ }^{2}$ Department of Agricultural and Bio-Systems Engineering, Iowa State University, Iowa, USA \\ ${ }^{3}$ Department of Chemical and Materials Engineering, University of Kentucky, Kentucky, USA \\ Correspondence: J. Seay, Department of Chemical and Materials Engineering, University of Kentucky, Kentucky, \\ USA. E-mail: Jeffrey.seay@uky.edu
}

\author{
Received: July 15, 2019 Accepted: August 10, $2019 \quad$ Online Published: September 29, 2019 \\ doi:10.5539/jsd.v12n5p112 URL: https://doi.org/10.5539/jsd.v12n5p112
}

\begin{abstract}
The topic of appropriate technology for the conversion of waste biomass into valuable products has often been overlooked in Sub-Saharan Africa. The influence of the type of technology, biomass type, and operating parameters such as; temperature, moisture content, etc. on the conversion process, is a barely known. This contribution aimed at studying pyrolysis of wood residues, and the specific objectives were; (1) characterisation of organic products (wood vinegar and tar) of pyrolysis of wood residues, (2) investigation of the effect of temperature and feedstock type on the yield of products and (3) to carry out an energy balance of the pyrolysis reactor system. Wood residues were pyrolysed in a cylindrical batch reactor at temperatures 300-350, 400-450 and $500-550^{\circ} \mathrm{C}$ and the organic were characterised using a gas chromatograph (GC) fitted with a flame ionisation detector (FID). The most notable compounds in the wood vinegar and tar were; alcohols, acids, furans, phenols, aldehydes, and ketones. The yield of vinegar, tar and char reduced significantly with an increase in temperature and the maximums were produced at $300-350^{\circ} \mathrm{C}$ whereas the yield of non-condensable gases increased with an increase in temperature. The type of feedstock used had no significant effect on the yield and distribution of products. The energy balance of the system revealed that the process was $78 \%$ efficient. The presence of the oxygenated aliphatic and aromatic hydrocarbons makes the wood vinegar and tar potential sources of chemicals and engine fuels. Preliminary trials with wood vinegar were lethal to black ants that are predominantly a menace to farmers in Sub-Saharan Africa.
\end{abstract}

Keywords: Sub-Saharan Africa, appropriate technology, pyrolysis, biomass, wood residues, wood vinegar, tar, characterisation, energy balance

\section{Introduction}

Over the past decade, biomass has been identified as a renewable source of energy with the great potential to replace petrochemicals (Ucar \& Ozkan, 2008). This has motivated a lot of research into biomass and bioenergy (Bridgwater, 2012; Mohamed, Kim, Ellis, \& Bi, 2016; Mourant et al., 2013; Paré, Bernier, Thiffault, \& Titus, 2011). According to Demirbas (2009), the biggest portion (64\%) of global biomass is produced by wood and wood waste. The processing of wood generates waste biomass in the form of wood sawdust, offcuts, bark and chips, which amount to over $45-55 \%$ of the entire input mass (Ogunwusi, 2014). In Sub-Saharan Africa, wood wastes are under-utilised leaving them to rot at the sawmills and this poses environmental and health issues such as pollution, greenhouse gas emissions, the formation of leachates, and blockage of sewer systems, watercourses and channels (Aiyeloja, Oladele, \& Furo, 2013; Owoyemi, Zakariya, \& Elegbede, 2016). Uganda, like other countries in Sub-Saharan Africa, South America and Asia is overwhelmed by excessive amounts of wood residues with no proper disposal and utilisation methods. Uganda approximately has an area of 241,551 sq. km of which, about $11 \%$ is currently under forestry and woodland coverage (UBOS, 2015). In 2013, Uganda produced 44.7 million tonnes of wood resources showing an increase of about $4.2 \%$ in productivity (UBOS, 2015). According to MWE (2013), licensed pit-sawyers in Uganda produce about $100,000 \mathrm{~m}^{3}$ of sawn wood annually and if the timber that goes unrecorded is factored in, the amount produced becomes $300,000 \mathrm{~m}^{3}$. However, with the reported $20-35 \%$ sawmilling recovery (Kaboggoza, 2011), more than $405,000 \mathrm{~m}^{3}$ of sawmilling waste is produced of which, less than $10 \%$ is utilised in briquette making by local companies such as 
Kampala Jellitone Suppliers Limited, Green Bioenergy, and Green Resources among others, leaving the rest to waste (Okello, Pindozzi, Faugno, \& Boccia, 2013).

The environmental problems associated with wood residues have motivated research into alternative methods in which the residues can be utilised. One promising method is the conversion of these residues into useful and value-added fuels to curb down the energy gap and also reduce the problems associated with the use of petrochemicals. Although there are a number of technologies for biomass conversion into useful energy such as; gasification, fermentation, torrefaction, etc., pyrolysis is the most modern and profound (Kan, Strezov, \& Evans, 2016). Pyrolysis is the thermochemical decomposition of biomass in the absence of oxygen and halogens at elevated temperatures (Choi, Jung, Oh, \& Kim, 2014; Mohan et al., 2014). Pyrolysis results into three products namely; solids (biochar), liquids (pyrolytic oil) and non-condensable gases (Rivilli, Alarcón, Isasmendi, \& Pérez, 2011; Theapparat, Chandumpai, Leelasuphakul, \& Laemsuk, 2014). The process occurs in three steps: the first being the loss of moisture and some volatiles, the second being the conversion of the unreacted residues into gases, volatiles and biochar and lastly, the third one being the slow chemical rearrangement of the biochar (Jeguirim \& Trouvé, 2009). Pyrolysis of waste wood biomass can ensure efficient utilisation of the natural resource and helps prevent environmental pollution caused by improper disposal. The utilisation of biofuels derived from pyrolysis of wood biomass has substantial environmental benefits such as; reduced fossil $\mathrm{CO}_{2}$ emissions, decreased global warming impacts due to low nitrogen and sulphur content of wood biomass and reduced fossil fuel reliance (Yorgun \& Y1ldı, 2015).

The quality and yield of the products of pyrolysis mainly depend upon the type of pyrolysis, operating parameters and biomass type. Pyrolysis operating parameters include; heating rate, temperature, type of feedstock, sweep gas flow rate, biomass moisture content, residence time, catalyst and mineral matter (Akhtar \& Saidina Amin, 2012; Önal, Uzun, \& Pütün, 2011; Xiu \& Shahbazi, 2012). Depending on the predetermined set of operating parameters, pyrolysis can be divided into three classes; slow, fast and flash pyrolysis (Jahirul, Rasul, Chowdhury, \& Ashwath, 2012). Slow pyrolysis occurs at slow heating rates of $0.1-10^{\circ} \mathrm{C} / \mathrm{s}$ with a process temperature range of $300-500^{\circ} \mathrm{C}$. It is characterised by longer residence time and produces char as the main product (Marshall, $\mathrm{Wu}, \mathrm{Mun}, \&$ Lalonde, 2014). On the contrary, fast pyrolysis occurs at relatively high heating rates $\left(10-200^{\circ} \mathrm{C} / \mathrm{s}\right)$, higher temperatures $\left(450-650^{\circ} \mathrm{C}\right)$, less residence time of 5 to 9 seconds and generates liquids as the main products at a yield of about $40-75 \%$ in practice (Yanik, Kornmayer, Saglam, \& Yüksel, 2007). Flash pyrolysis takes place at extremely high heating rates greater than $100^{\circ} \mathrm{C} / \mathrm{s}$ and at shorter residence time than fast pyrolysis (Shuangning, Weiming, \& $\mathrm{Li}$, 2005). This produces more of the incondensable gases which are currently of less interest and it occurs at higher temperatures of up to $1000^{\circ} \mathrm{C}$ (Jahirul et al., 2012). If the purpose of biomass pyrolysis were to maximise the yield of liquid products, a high heating rate, low temperature, and short gas residence time process would be required whereas a low temperature and low heating rate would be chosen for a high char production. If the purpose were to maximise the yield of non-condensable gases, a low heating rate, long gas residence time and high-temperature process would be preferred (Demirbas, 2004). Over the past decade, several studies have been conducted to investigate the effect of different operating parameters on the quality and yield of products for different types of biomass. Some of the studies include; Mango seed waste (Lazzari et al., 2016), Banana wastes (Omulo et al., 2017), Spent Coffee Grounds (Bispo et al., 2016), Peach cores (Moraes et al., 2012), Pine shaving (Keiluweit, Nico, Johnson, \& Kleber, 2010), Aquatic biomass (Muradov, Fidalgo, Gujar, \& T-Raissi, 2010), Pine needles (B. Chen, Zhou, \& Zhu, 2008), Eucalyptus sawdust (Faccini, Vecchia, Ribeiro, Zini, \& Caramão, 2013), Peanut straw (Tong, Li, Yuan, \& Xu, 2011), Poultry litter (Cantrell, Hunt, Uchimiya, Novak, \& Ro, 2012), Pinewood (Liu, Zhang, \& Wu, 2010), Coconut fibres (Almeida et al., 2013), Poplar wood (Kloss et al., 2012) all with different types of pyrolysis reactors and operating parameters.

Presently, there is no comprehensive research about the pyrolysis of biomass in Sub-Saharan Africa and influence of operating parameters is unknown. Furthermore, the pyrolysis reactor used in this study was specifically designed as an Appropriate Technology for developing regions (Joshi \& Seay, 2016) and has not been used elsewhere. Omulo et al. (2017) did preliminary work on the reactor in which they pyrolysed banana wastes and characterised the organic products. There is a need to study other forms of biomass, operating parameters, and characterisation of the reactor. Therefore, the main objectives of this study were; (1) to characterise the organic products of pyrolysis of wood residues, (2) to investigate the effect of temperature and tree species on the yield and distribution of products and (3) to carry out an energy balance of the reactor system.

Residues of pine and eucalyptus were considered in this study because they are the most commonly grown and harvested exotic tree species in Uganda for saw log and plywood production (Kaboggoza, 2011). Pine dominates government plantations to a margin of more than $80 \%$ (Kaboggoza, 2011). Although eucalyptus has been 
traditionally used for pole and firewood, it is also currently recognised as a reliable source of timber used for heavy and light construction projects. Private plantations are mostly made up of pine at $54 \%$ followed by eucalyptus at $17 \%$ (Kaboggoza, 2011).

\section{Materials and Methods}

\subsection{Study Area and Experimental Materials}

The study was conducted at Makerere University Agricultural Research Institute Kabanyolo (MUARIK) which is located at latitude $0.45^{\circ}$ and longitude $32.62^{\circ}$ about $21 \mathrm{~km}$ north of Kampala city. The wood residues used in the study were obtained from Bwaise sawmills, the second largest market for sawn wood in Kampala after Ndeeba producing over $3750 \mathrm{~m}^{3}$ of sawn wood per year (WWF, 2012). The residues were collected at the time of milling to ensure purely one species per sample is obtained. The age of the trees was not important in the study because commercial tree species are always harvested at a specific uniform age.

\subsection{Initial Characterisation of Biomass}

Proximate and elemental analyses were carried out according to standard procedures i.e. ASTM E 872 for the volatile matter, ASTM E871 for moisture content, ASTM D1102 ash content and fixed carbon by difference using a Thermostep thermogravimetric analyser (TGA) made by ELTRA. For elemental analysis, the standard methods according to ASTM E 777 for carbon and hydrogen, ASTM E778 for nitrogen and ASTM E775 for sulphur. Oxygen was determined as a difference from 100. An elemental analyser model CHS 580 also made by ELTRA was used.

\subsection{Pyrolysis Process and Experiments}

A cylindrical batch reactor with a volume of 37.6 litres designed and fabricated for developing regions by the University of Kentucky Appropriate Technology and Sustainability (UKATS) Research group at University of Kentucky was used for pyrolysis experiments (Joshi \& Seay, 2016). The reactor used was powered by a rocket stove that utilises wood fuel as an energy source. The energy losses from the system were reduced by insulating the rocket stove with an outside layer packed with vermiculite. The pyrolysis system had a two-stage condensation system, the first one for removal of heavy components of pyrolysis vapors (tar) and the second one (a car radiator) for removal of volatile vapors (vinegar). The system had two storage containers, one for collecting tar and the second one for collecting vinegar as shown in Figure 1. The non-condensable vapors (NCGs) were vented through a pipe outside of the workshop and no sampling was done. 


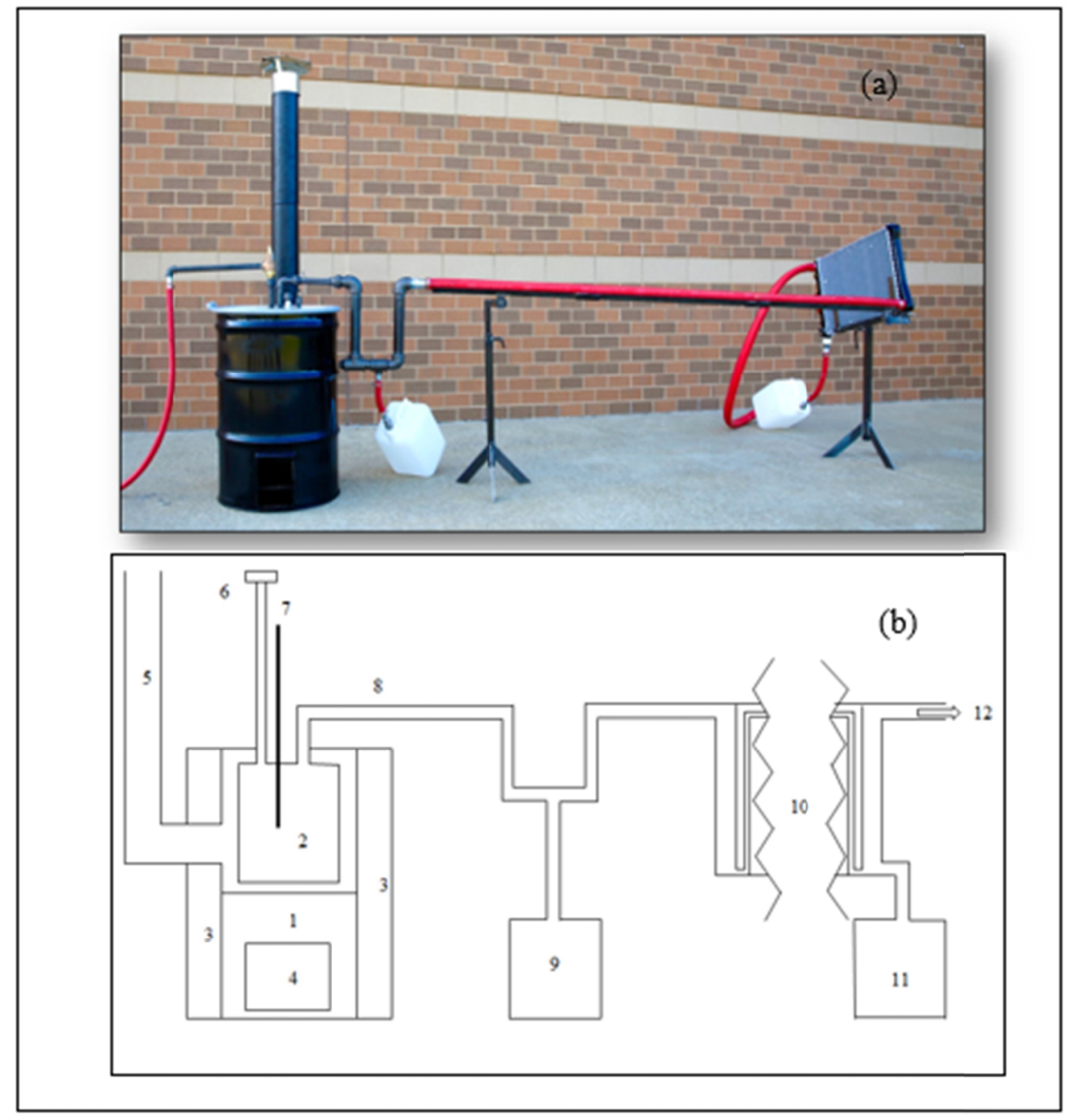

Figure 1. Pyrolysis system used in the study: (a) picture, (b) schematic diagram: (1) rocket stove, (2) pyrolysis reactor, (3) rocket stove insulation, (4) fuelwood loading point, (5) rocket stove chimney, (6) pressure relief valve, (7) thermocouple, (8) reactor outlet pipe, (9) tar storage container, (10) radiator, (11) vinegar storage container, (12) NCG vent

In order to determine the effect of using different tree species as feedstock on the yield and distribution of pyrolysis products, residues of pine, eucalyptus and a mixture of pine and eucalyptus in ratio 1:1 were pyrolysed each independently in triplicate. Pine and eucalyptus residues were mixed due to the fact that most sawmills in Uganda process different wood species, but do not sort the wood wastes according to species. So, it was meant to investigate the effect of mixing residues from different species on the quality and yield of products. Statistical data analyses were performed using the $\mathrm{R}$ software version 3.2.2.

The effect of temperature was investigated by running pyrolysis experiments at temperature ranges of 300-350, 400-450 and $500-550^{\circ} \mathrm{C}$ ramped at an average heating rate of $10{ }^{\circ} \mathrm{C} / \mathrm{min}$. A starting temperature range of $300-350^{\circ} \mathrm{C}$ was selected because it is the temperature at which cellulose and hemicellulose decomposition begins leading to the formation of biochar, bio-oil, and gases (Jeguirim \& Trouvé, 2009). Temperature ranges were used in the experiments due to the fact that the temperature was controlled manually by removing and adding fuelwood into the rocket stove and therefore it was not possible to maintain a point temperature. The temperature was measured by a thermocouple fitted inside the reactor connected to a digital multimeter manufactured by Extech technologies. Due to the absence of an automated system, the heating rate was controlled manually by alternately reducing and increasing the rate of loading wood fuel into the rocket stove. 


\subsection{Characterisation of Wood Vinegar and Tar}

Every after each run, wood vinegar and tar were weighed and stored for analysis and characterisation. The remaining solid (biochar) was removed from the reactor and weighed. The gas yield was determined by a mass balance of the reactor. The tar and wood vinegar from the different types of feedstock i.e. pine residues, eucalyptus residues and the 1:1 blend of pine and eucalyptus were labelled as shown in Table 1 and then taken for analysis. A gas chromatograph (GC) model 7820A from Agilent Technologies was used to characterise the wood vinegar and tar. Characterisation experiments were conducted using an Agilent DB-624 UI column with a length of $30 \mathrm{~m}$, a diameter of $0.250 \mathrm{~mm}$, and a film thickness of $1.40 \mu \mathrm{m}$. The GC was equipped with a flame ionisation detector (FID). The temperature program began with an initial temperature of $35^{\circ} \mathrm{C}$, held for 1 minute, and then helium was used to carry the gas ramped at $120^{\circ} \mathrm{C}$ /minute to $26^{\circ} \mathrm{C}$ and held for 10 minutes, for a total run time of 34 minutes.

Table 1. Labels for the organic products of pyrolysis of different types of feedstock

\begin{tabular}{ll}
\hline Product & Label \\
\hline Pine vinegar & PV \\
Pine tar & PT \\
Eucalyptus vinegar & EV \\
Eucalyptus tar & ET \\
The mixture of Pine and Eucalyptus vinegar & PEV \\
The mixture of Pine and Eucalyptus tar & PET \\
\hline
\end{tabular}

Peak identification was done by matching the retention times of the chromatographic column samples with standard chromatograms made at UKATS. The peak area normalisation method was used to determine each compound's percentage content (Omulo et al., 2017). The $\mathrm{pH}$ values for all the wood vinegar and tar samples were determined using a pH meter model HI $2215 \mathrm{pH} / \mathrm{ORP}$ whereas densities were estimated by determining the masses of the samples and then divide by their respective volumes.

\subsection{The Energy Balance of the Reactor}

The energy balance of the reactor was carried out based on both the energy input and energy output of the reactor and the efficiency was estimated using Equation 1

$$
\text { Energy Efficiency }={ }^{E_{o}} / E_{i}
$$

Where; $E_{i}=$ the input energy and $E_{0}=$ the total output energy

The amount of wood fuel consumed by the rocket stove per run was determined by weighing using a spring balance and then Equation 2 was used to estimate the energy input into the rocket stove.

$$
E_{i}=M_{F} \times H H V_{F}
$$

Where; $M_{F}=$ amount wood fuel consumed per a given run and $H H V_{F}=H H V$ for the firewood used.

The energy output of the reactor was estimated by summing up the energy stored in the biochar, tar and wood vinegar and the NCGs. Wood vinegar and tar were combined as it was done by (Pattiya, 2011) and considered as one product referred to as bio-oil for the energy balance calculations. The energy stored in the biochar, bio-oil, and NCGs was estimated using Equations 3, 4 and 5 respectively;

$$
\begin{aligned}
E_{B} & =M_{B} \times H H V_{B} \\
E_{L} & =M_{L} \times H H V_{L} \\
E_{G} & =M_{G} \times H H V_{g}
\end{aligned}
$$

Where; $E_{B}=$ energy stored in the produced biochar, $M_{B}=$ mass of the produced biochar for a given run, $H H V_{B}=$ HHV for the biochar, $E_{L}=$ energy stored in the bio-oil, $M_{L}=$ mass of the produced bio-oil (tar + vinegar) for a given run, $H H V_{L}=\mathrm{HHV}$ for the produced bio-oil, $E_{G}=$ energy stored in the NCG, $M_{G}=$ mass of the produced NCGs, $H H V_{G}=$ HHV for the NCGs 
The higher heating values (HHV) for biomass (pine and eucalyptus residues), biochar and bio-oil were determined using a bomb calorimeter model IKA C2000 basic according to standard procedures ASTM E711-87 for biomass and biochar and DIN 51900-1 for bio-oil. The HHV for NCGs was estimated using Equation 6 (Raveendran \& Ganesh, 1996).

$$
H b \approx H_{c} \times Y_{c}+H_{l} \times Y_{l}+H_{g} \times Y_{g}
$$

Where; $H_{b}=$ HHV for biomass, $H_{c}=$ HHV for biochar, $H_{l}=$ HHV for bio-oil, $H_{g}=$ HHV for NCGs, $Y_{c}=$ Yield of biochar, $Y_{l}=$ Yield of bio-oil, $Y_{g}=$ Yield of NCGs

\subsection{Preliminary Trials of Vinegar on Black Ants}

The trials of vinegar on black ants were conducted at Makerere University Agricultural Research Institute (MUARIK). Active black ants were treated with freshly prepared vinegar and then observed for 20 minutes. Figure 2 shows the team of researchers from Makerere University and University of Kentucky observing the black ants after a treatment with vinegar at MUARIK.

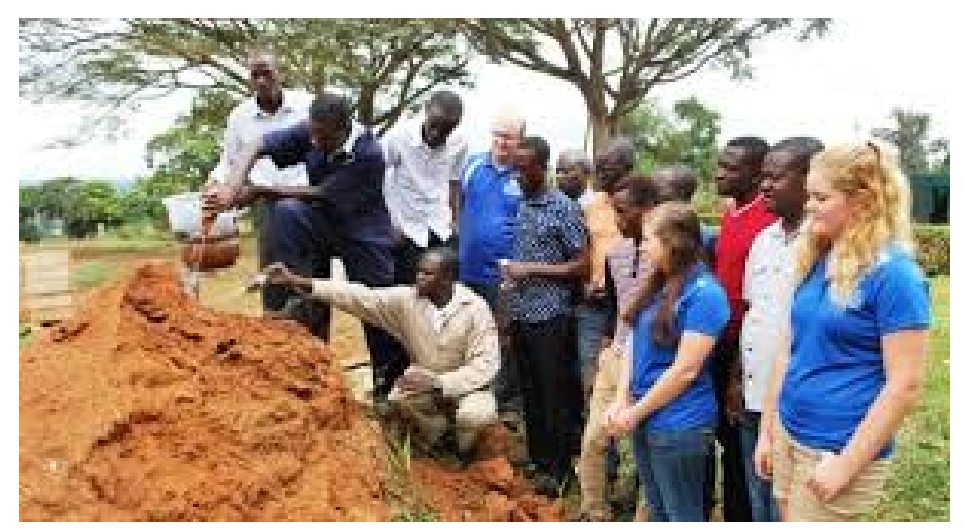

Figure 2. A team of researchers from Makerere University and University of Kentucky observing black ants after a treatment with freshly prepared vinegar

\section{Results and Discussions}

\subsection{Initial Characterisation of the Biomass Feedstocks}

Results of proximate and elemental analysis for both pine and eucalyptus wood residues are presented in Table 2. Analysis of variance indicated significant difference $(\mathrm{p}<0.05)$ in the chemical composition of eucalyptus and pine residues for the volatile matter, fixed carbon, moisture content, ash content, elemental carbon and oxygen. This variation in the chemical composition has a great effect on the thermal utilisation of biomass and therefore has an effect on the quality and quantity of pyrolysis products (Obernberger, Brunner, \& Bärnthaler, 2006). A high fixed carbon and ash content can result in increased biochar yield from the pyrolysis process whereas a high content of volatiles can result in increased bio-oil yield from the pyrolysis process (Lazzari et al., 2016). There was no significant difference $(\mathrm{p}>0.05)$ for the composition of hydrogen and nitrogen.

Table 2. Proximate and elemental analysis results of pine and eucalyptus mill residues

\begin{tabular}{llllllllll}
\hline & $\mathrm{M}^{\mathrm{a}}$ & $\mathrm{VM}^{\mathrm{b}}$ & $\mathrm{FC}^{\mathrm{b}}$ & $\mathrm{A}^{\mathrm{b}}$ & $\mathrm{C}$ & $\mathrm{H}$ & $\mathrm{N}$ & $\mathrm{S}$ & $\mathrm{O}^{\mathrm{c}}$ \\
\hline Pine & 28 & 83.2 & 16.5 & 0.3 & 52.1 & 6.0 & 0.2 & 0.02 & 41.68 \\
Eucalyptus & 30 & 74.0 & 21.9 & 4.1 & 73.28 & 3.2 & 0.22 & 0.05 & 23.25 \\
\hline
\end{tabular}

Note.; ${ }^{\mathrm{a}}$ as received basis; ${ }^{\mathrm{b}}$ on dry ash free basis, ${ }^{\mathrm{c}}$ by difference

The values of proximate and elemental analysis obtained in this study are not so much different from those obtained in other studies. According to Cuiping, Chuangzhi, Yanyongjie, and Haitao (2004), the volatile matter of forestry biomass lies in the range of $61-76 \%$. The moisture content of the pine and eucalyptus was much higher than that used in other studies. Biomass with lower moisture content is recommended for thermochemical conversion processes. Therefore, pine and wood residues required drying to lower moisture contents before it 
could be used. The low nitrogen and sulphur contents observed in this study make the wood residues recommendable for thermo-chemical conversion due to its environmental protection potential (Cuiping et al., 2004).

\subsection{Characterisation of the Wood Vinegar and Tar}

The chromatograms for pine vinegar, eucalyptus vinegar, pine tar, and eucalyptus tar are shown in Figure 2a, b, c, and $d$ respectively. As shown in Figures $3 a$ and $b$ the most notable compounds in pine and eucalyptus vinegar were found to be; methanol, ethanol, acetic acid, acetaldehyde, furfural, methyl-propyl-ketone (MPK), propanoic acid, acetone, and 3-hexanone. The notable compounds of pine and eucalyptus tar were; acetic acid, acetaldehyde, furfural, methyl-propyl-ketone (MPK), propanoic acid, acetone, 3-hexanone, and guaiacol. All the vinegar samples were found to contain methanol and ethanol while no alcohols were found in tar samples. This was due to the volatile nature and low molecular weight of methanol and ethanol and therefore they were only collected during the second condensation stage. The only compound that was found present in tar but absent in vinegar was guaiacol. This may due to the fact that guaiacol has a relatively high molecular weight and therefore did not surpass the first condensation stage where tar was collected.

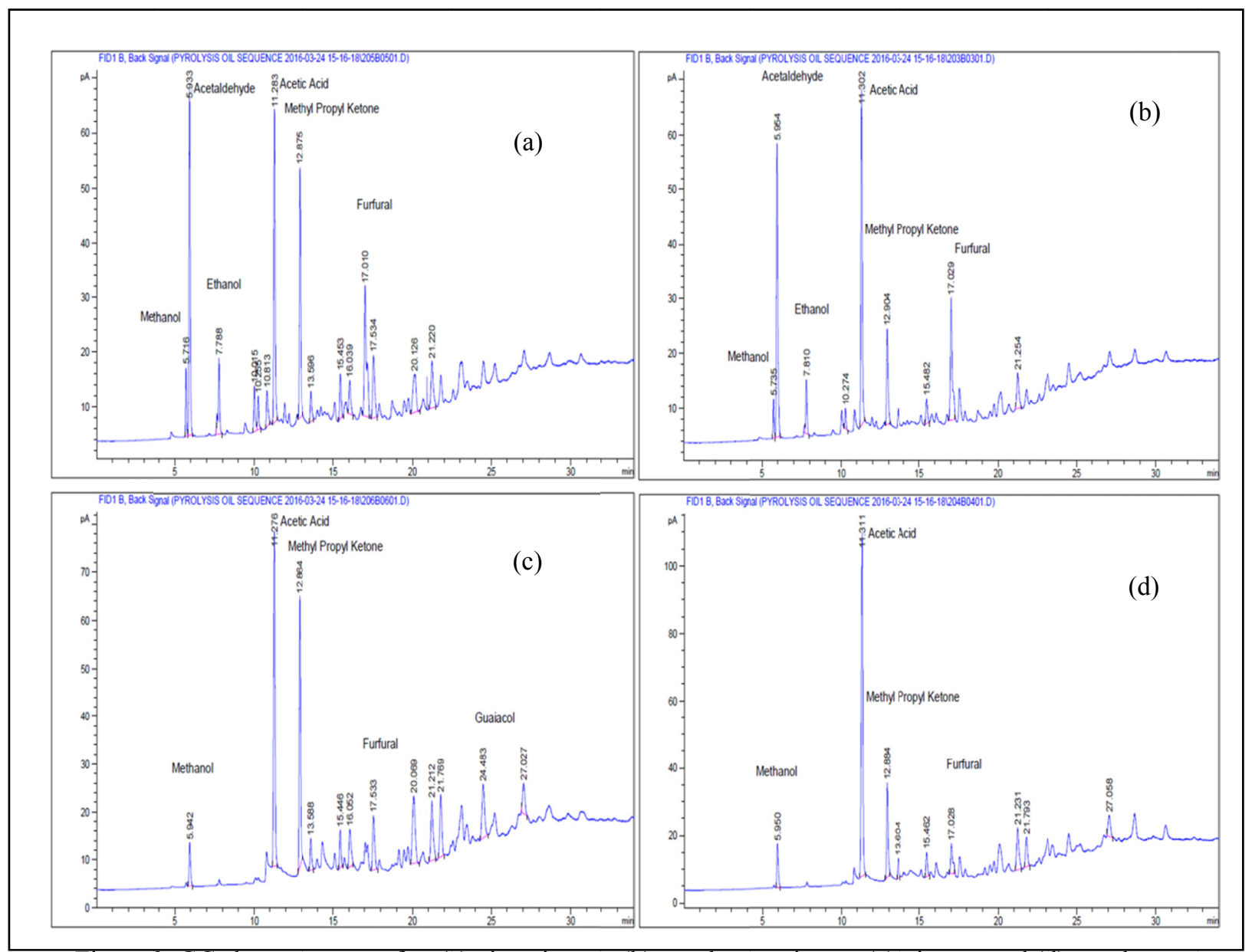

Figure 2. GC chromatograms for: (a) pine vinegar, (b) eucalyptus vinegar (c) pine tar and (d) eucalyptus tar

Identified compounds can be divided into four different classes of aliphatics, monoaromatics, oxygenated compounds, and polyaromatic compounds. Monoaromatic compounds include; Furans such as furfural, phenols, benzene, and their derivatives. Aliphatics are mainly consisting of alkanes and alkenes and their derivatives. Oxygenated compounds composed of ketones, aldehydes and carboxylic acid (Aysu \& Küçük, 2014). Phenols and derivatives such as 2-methoxy phenol (guaiacol), are primarily formed by decomposition of lignin unit of biomass and the aldehydes, alcohols, and ketones are formed by the degradation of cellulose and hemicellulose fraction of biomass (Ningbo, Baoling, Aimin, \& Juanjuan, 2015; Sun, Heng, Sun, \& Chen, 2011; Wang, Guo, Wang, \& Luo, 2011). The chemical composition of the organic products in the study was in agreement with many other studies on wood-derived pyrolysis oils that reported the existence of complex oxygenated aliphatic 
and aromatic hydrocarbons in the organic products (Y. Lee et al., 2013; Sanna, Li, Linforth, Smart, \& Andrésen, 2011; Yorgun \& Y1ldız, 2015). It can be concluded from this chemical composition that the organic products cannot only be used as an engine fuel but also a source of different chemicals such as phenols, aldehydes, alcohols, and acids among others.

\subsection{The Relative Composition of the Compounds in the Produced Tar and Vinegar}

Figure 3 shows the relative chemical compositions of vinegar and tar produced from the different feedstock. The percentages are based on the retention times of the compounds in the gas column and the peak area of the signal under the chromatogram. It is quite clear that the most abundant compounds were; acetic acid $(50.6 \%)$ in eucalyptus tar, acetaldehyde (27.0\%) in eucalyptus vinegar, MPK (20.7\%) in pine tar and furfural (16.0\%) in eucalyptus vinegar all percentages on measured on water free basis. Generally, tar had a higher concentration of acetic acid and MPK than vinegar whereas vinegar had a higher concentration of furfural, acetaldehyde. Eucalyptus tar had the highest concentration of acetic acid followed by pine-eucalyptus blend tar and then pine tar. Tar contained no ethanol and methanol whereas vinegar contained no guaiacol. This is due to the fact that ethanol and methanol have a low molecular weight and can only be collected during the second condensation stage. Guaiacol has a very high molecular weight and therefore could not go beyond the first condensation stage.

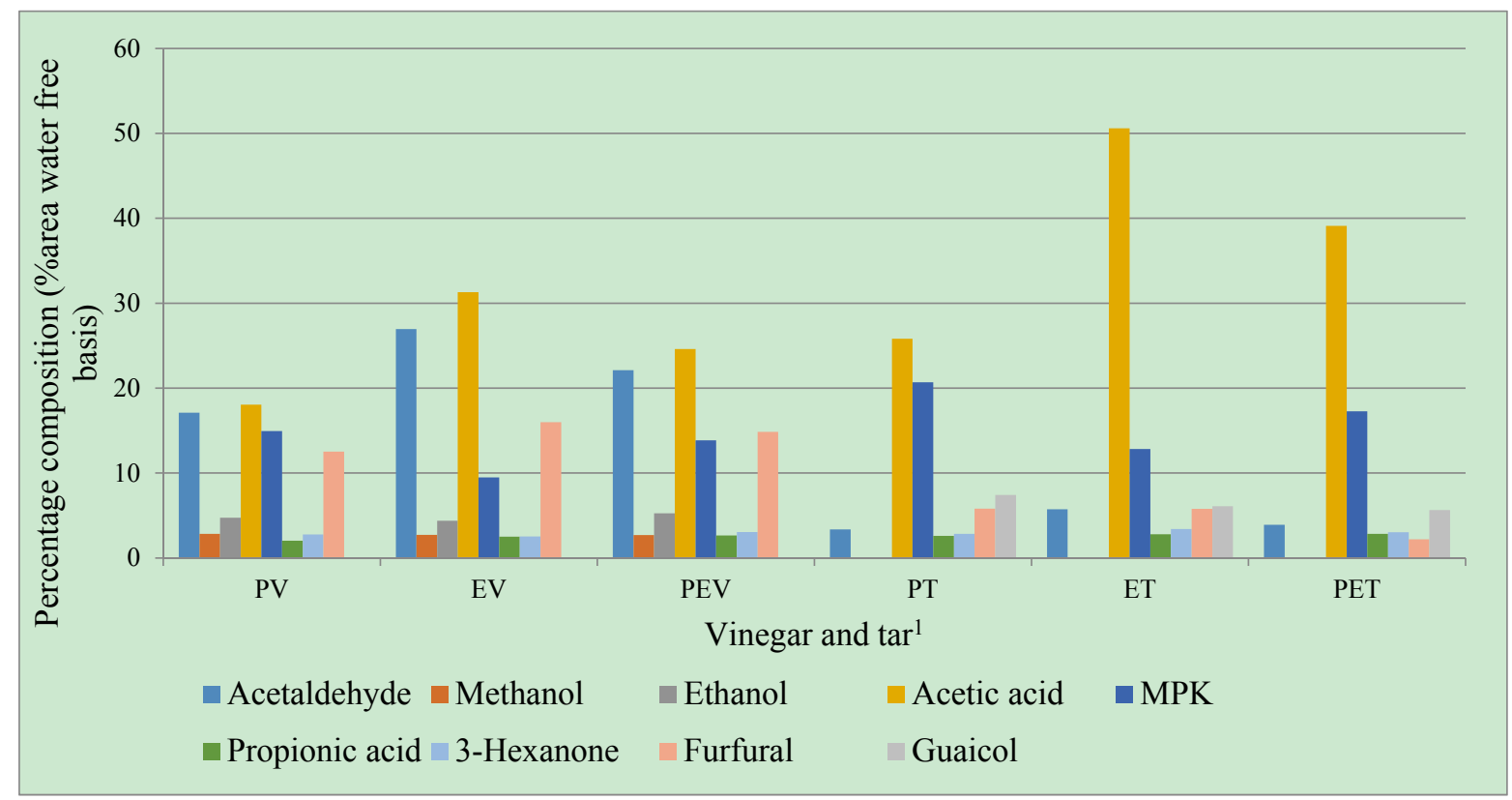

Note $; \mathrm{PV}=$ Pine Vinegar, EV = Eucalyptus Vinegar, $\mathrm{PEV}=$ Pine-Eucalyptus blend Vinegar, $\mathrm{PT}=\mathrm{Pine}$ Tar, $\mathrm{ET}=$ Eucalyptus Tar, PET = Pine-Eucalyptus blend Tar.

Figure 3. Relative compositions of compounds found in the vinegar and tar from pine and eucalyptus wood residues

It is more realistic to treat the identified compounds as mixtures of a few groups with similar properties rather than different individual organic compounds (Vispute \& Huber, 2009). Groups identified for pine and eucalyptus vinegar and tar were alcohols, furans, ketones, acids, phenols, and aldehydes. Figure 4 shows the relative percentage of these groups of compounds. Eucalyptus products had a higher percentage of acids, aldehydes, and furfurals whereas those of pine had higher ketones, alcohols, and phenols. This might be due to the difference in the chemical composition of pine and eucalyptus residues as depicted by proximate and elemental analysis. Generally, vinegar had a higher concentration of furfurals, aldehydes while tar contained mainly acids and ketones. Due to their low molecular weight and volatility, no alcohols were detected in tars which imply they were only collected during the second condensation stage i.e. in vinegar. Phenols were only detected in tars i.e. first condensation stage and not in vinegar due to their high molecular weight. 


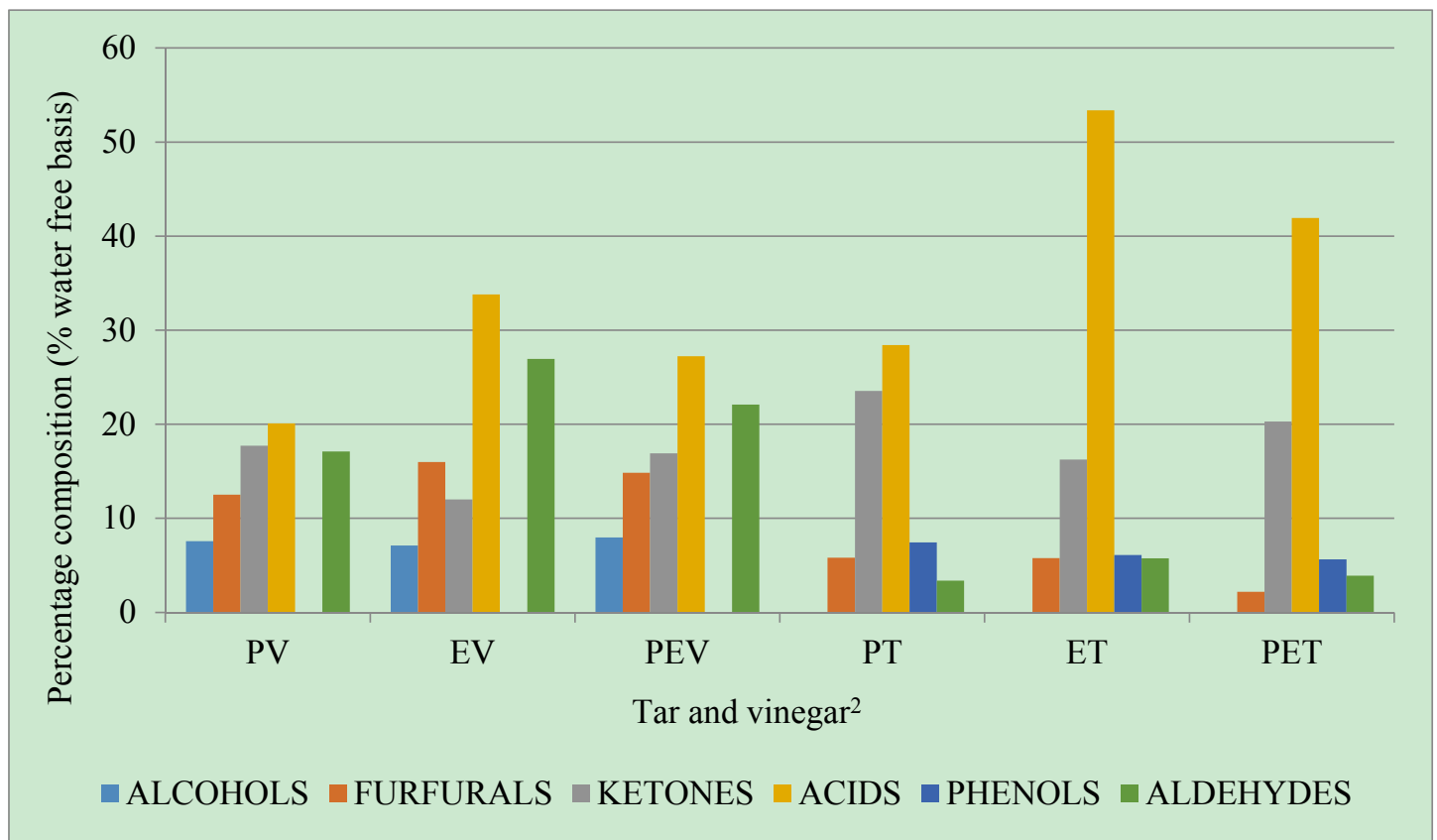

Note.; PV = Pine Vinegar, EV = Eucalyptus Vinegar, $\mathrm{PEV} \mathrm{=} \mathrm{Pine-Eucalyptus} \mathrm{blend} \mathrm{Vinegar,} \mathrm{PT}=$ Pine Tar, ET = Eucalyptus Tar, PET = Pine-Eucalyptus blend Tar.

Figure 4. Different classes of compounds found in vinegar and tar produced from pine and eucalyptus wood residues

Acids and ketones were the most abundant compounds in the products while alcohols, aldehydes, phenols, and furans were the least abundant. The same results were obtained by $\mathrm{Wu}$ et al. (2015) during his study on wood vinegar obtained from fir and bamboo wood residues. He found out that the components with lower content were aldehydes and alcohols and they were not affected by the pyrolysis temperature. Another form of grouping organic compounds is by combining aliphatics, aromatic and polar compounds. The organic products of pyrolysis are highly oxygenated multifaceted mixtures of hundreds of individual chemicals that can be grouped into many various classes of compounds (Pütün, Önal, Uzun, \& Özbay, 2007). The relative percentage of aliphatic and aromatic in the organic products was $33 \%$ and $23.4 \%$ respectively making approximately a total of $56 \%$ of aliphatic and aromatic sub-fractions. Consequently, this makes the tar and vinegar seem to be appropriate raw materials for the production of hydrocarbons and chemicals.

\subsection{Physiochemical Properties of the Products}

Table 3 shows the physiochemical properties of the organic products of pyrolysis of pine and eucalyptus wood residues. The properties studied were only $\mathrm{pH}$ and density due to resource constraints. It is very important to understand the physiochemical properties of pyrolysis oils in order to identify the appropriate applications and methods of upgradation. PH and density values for pine vinegar, eucalyptus vinegar, pine-eucalyptus vinegar, pine tar, eucalyptus tar, and pine-eucalyptus tar are presented. Generally, tars were slightly more acidic than vinegar. Eucalyptus tar was observed to be the most acidic product whereas pine vinegar was the least.

Table 3. Physiochemical properties of organic products of pyrolysis of different feedstock

\begin{tabular}{llll}
\hline Product & Yield $(\mathrm{wt} \%)$ & Density $/ \mathrm{kgm}^{-3}$ & $\mathrm{pH}$ \\
\hline Pine Vinegar & 9.23 & 1078.84 & 4.2 \\
Eucalyptus Vinegar & 9.12 & 1151.95 & 3.8 \\
Pine-Eucalyptus blend Vinegar & 8.14 & 1361.53 & 3.3 \\
Pine Tar & 14.31 & 1069.32 & 3.2 \\
Eucalyptus Tar & 10.77 & 1232.27 & 2.5 \\
Pine-Eucalyptus blend Tar & 10.43 & 1312.05 & 3.0 \\
\hline
\end{tabular}


All the products were acidic since their $\mathrm{pH}$ values lie in the range below 4.5 . This is actually the typical $\mathrm{pH}$ range for pyrolysis organic products as can be seen from (Omulo et al., 2017; Pattiya, 2011; Tsai, Lee, \& Chang, 2006). The low $\mathrm{pH}$ of the tar and wood vinegar is caused by the presence of carboxylic compounds such as acetic acids and propionic acid. It is important to note that the $\mathrm{pH}$ value is one of the important properties of pyrolysis oils as it indicates the corrosive effects it might impose on equipment such as pipelines and engines. Piskorz, Majerski, Radlein, Scott, and Bridgwater (1998) suggested that careful and appropriate material selection is the solution when dealing with the corrosive biofuels. Acceptable materials include some olefin materials and stainless steel.

\subsection{Effect of the Final Pyrolysis Temperature on the Yield and Distribution of Products}

Generally, the yield of biochar, tar, and vinegar was observed to decrease while that of NCGs increased as the temperature increased for the studied temperature range. The same observation was made for all the three types of feedstock used in the study. Analysis of variance indicated that there was a significant difference $(p<0.05)$ in the products yield and distribution at different temperatures. This finding is in agreement with other studies where lower biochar yields and higher gas yields were observed for increasing temperature in spite of employing different pyrolysis systems and feedstock (Asadullah et al., 2007; Luo et al., 2004; Şensöz, Demiral, \& Gerçel, 2006). The process of pyrolysis conversion is greatly affected by the heating rate and the final pyrolysis temperature (Akhtar \& Saidina Amin, 2012; Xiu \& Shahbazi, 2012). Figure 5 shows the yield and distribution of biochar, tar, vinegar, and NCGs at temperatures $300-350,400-450,500-550^{\circ} \mathrm{C}$.

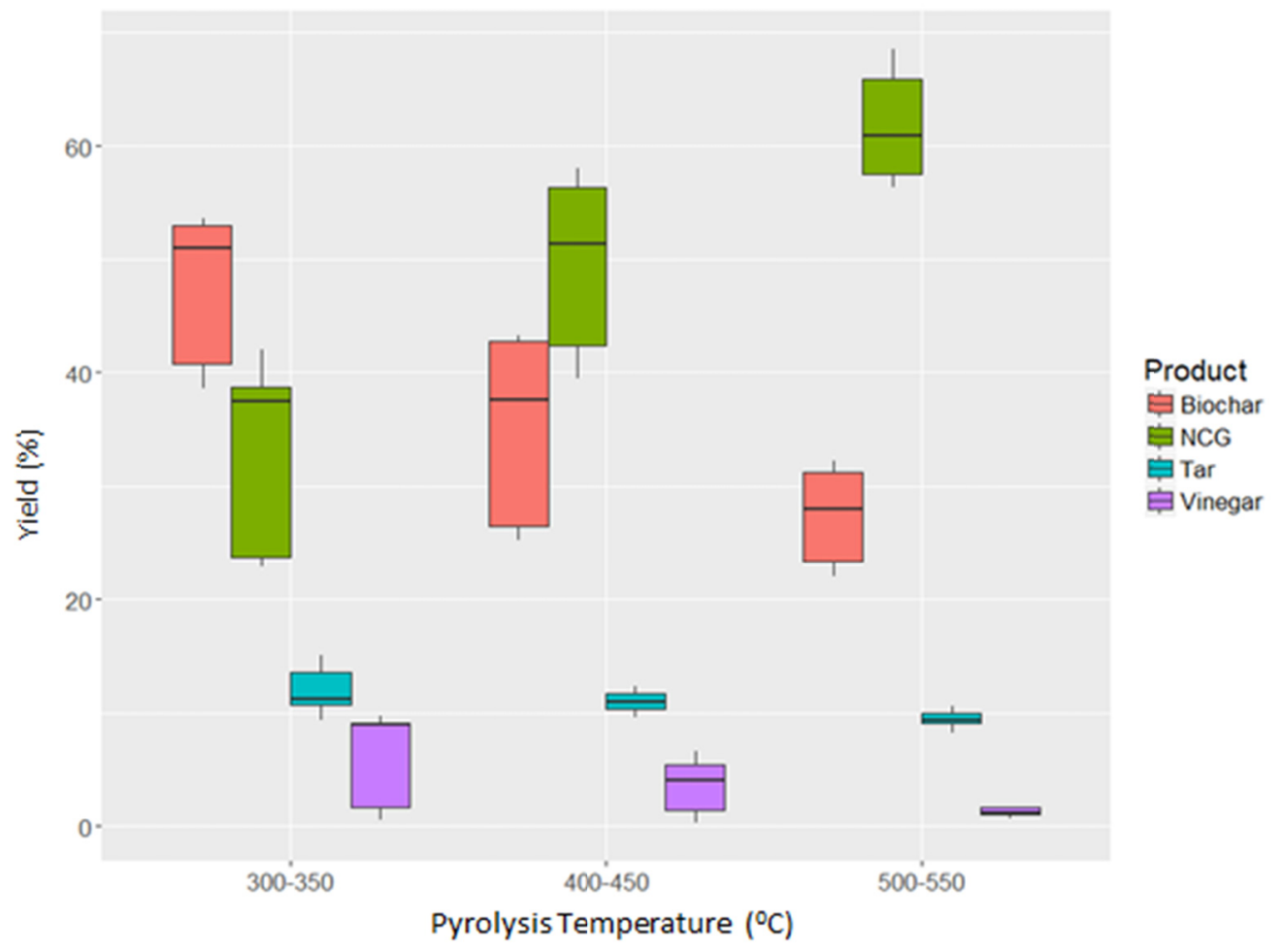

Figure 5. Effect of temperature on the yield and distribution of pyrolysis products

By increasing the final pyrolysis temperature from $300-350$ to $400-450$ and $500-400^{\circ} \mathrm{C}$, the biochar yield decreased from $48 \%$ to $35 \%$ and then $28 \%$ as shown in Figure 6 . The same behaviour was reported by several other researchers (Aysu \& Küçük, 2014; Önal et al., 2011; Uzun \& Sarioğlu, 2009) who observed biochar yield reduction with an increase in temperature. The reduction of biochar yields when the temperature is increased is due to the fact that at elevated temperatures, biomass undergoes greater primary decomposition and also the formed biochar may undergo secondary thermal decomposition before it is entrained out of the reaction zone. Thermal degradation of cellulose takes place in two forms of reactions; a gradual decomposition, degradation and charring at lower temperatures, and fast volatilisation followed by the development of levoglucosan at higher temperatures (Demirbas, 2004). According to Shafizadeh (1982), the degradation of cellulose to a more stable anhydrocellulose is dominant at temperatures below $300^{\circ} \mathrm{C}$ which gives a higher biochar yield. The reduced formation of char at the higher heating rate is accompanied by an increased formation of tar. The net 
effect is a decrease in the volatile fuel production and a decreased yield of biochar as cellulose is converted to levoglucosan at temperatures above $350^{\circ} \mathrm{C}$ (Demirbas, 2004).

Like char, the yield of tar and vinegar was observed to decrease slightly as the temperature increased. The findings of this study are in agreement with those in some of the existing literature (Heidari et al., 2014; Wu et al., 2015; Yanik et al., 2007) who reported higher yields and quality of bio-oil at lower temperatures. (Wu et al., 2015) reported that the optimum temperature for the preparation of wood vinegar by slow pyrolysis is $350^{\circ} \mathrm{C}$. The decrease in the liquid yield may due to the secondary cracking of some ingredients contained in the liquid product and pyrolysis vapours with rising temperatures because they are thermally unstable products (Demiral \& Ayan, 2011; Park et al., 2008; Pattiya, 2011; Pattiya \& Suttibak, 2012). However, some researchers have reported an increase in the yield of tar and vinegar with an increase in temperature (Ateş \& Işıkdağ, 2009; González et al., 2005). The difference between the results obtained in this study and those by other researchers is due to the difference in pyrolysis systems used and feedstock. For example, Ateş and Işıkdağ (2009) used a fixed bed reactor and corncob as feedstock and also the temperature range studied was between $300-800^{\circ} \mathrm{C}$ whereas, González et al. (2005) studied pyrolysis of almond shells in a fixed bed reactor. From this study, it can be concluded that the optimum temperature for production of the liquid products of pyrolysis from wood residues is $300-350^{\circ} \mathrm{C}$.

Unlike biochar, tar, and vinegar, the yield of NCGs increased with increase in temperature. Similar results have been observed by several other researchers (Heidari et al., 2014; Wei et al., 2006; Zheng, 2008). The increase of gas yields with increasing temperature is possibly due to a combination of secondary thermal cracking of the evolved pyrolysis vapours and the char secondary decomposition (Gerçel, 2011; Park et al., 2008; Pattiya, 2011; Pattiya \& Suttibak, 2012; Yanik et al., 2007). It may be concluded that secondary reactions of the volatile liquid product and further decomposition of the char particles proceeded in the reactor with increasing pyrolysis temperature (Uzun \& Sarioğlu, 2009). The pyrolysis process can be adjusted to favour biochar, pyrolytic oil, gas, or methanol production with $95.5 \%$ fuel to feed efficiency (Demirbas, 2004). Basing on the results from this study, it can be concluded that the production of NCGs can be optimised at higher temperatures.

\subsection{Effect of Feedstock on the Yield and Distribution of Products}

Figure 6 shows the yield and distribution of biochar, tar, vinegar and NCG for different sets of feedstocks i.e. pine, eucalyptus, and pine-eucalyptus blend. Analysis of variance indicated no significant difference in the yield and distribution of products for different types of feedstock. Though pine and eucalyptus had a different chemical composition as depicted by proximate and elemental analysis, it didn't have any significant effect on the yield and distribution of products. Yanik et al. (2007) reported similar results during his study on pyrolysis of corncob, straw and oregnum stalks. However, several other researchers have reported contrary observations (G. Chen, Andries, Luo, \& Spliethoff, 2003; Mullen et al., 2010; Tsai et al., 2006). The differences between the results are due to differences between reactor types used, residence times and types of pyrolysis. For example, Tsai et al. (2006) did experiments on fast pyrolysis which normally produces different results from those of slow pyrolysis which was done in the current study. In addition, they applied induction heating which produces shorter residence times than wood fuel used in the current study. More still, Mullen et al. (2010) fast pyrolysed corn stover and corn cobs in a pilot scale fluidised bed reactor and this, might have caused the difference in results since it is known that different types of reactors can produce results. 


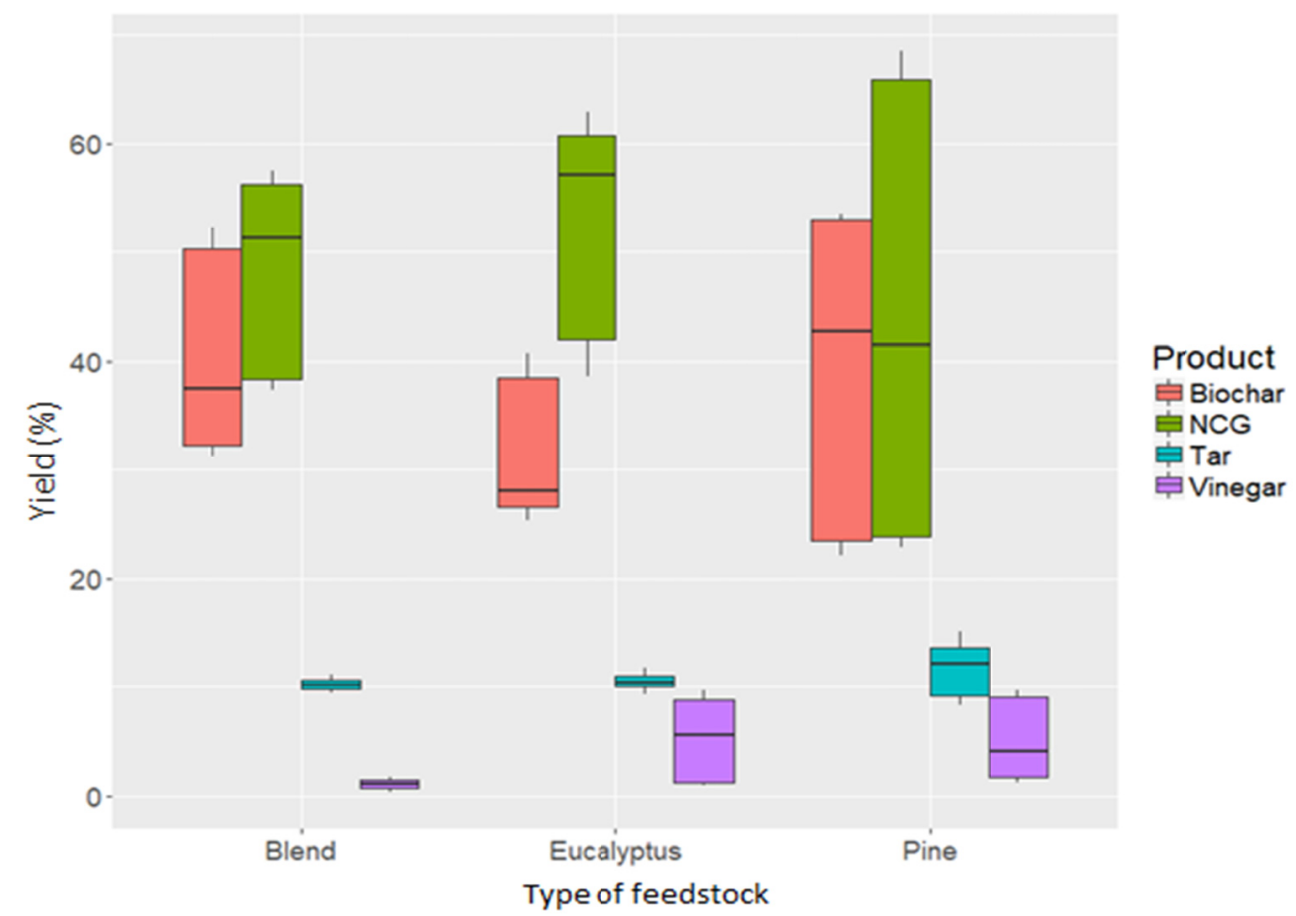

Figure 6. Effect of feedstock on the yield and distribution of pyrolysis products

\subsection{Potential Applications of the Wood Vinegar and Tar}

Over the past decades, several studies have indicated the potential applications of the organic products of pyrolysis (Cao et al., 2011; Mohan et al., 2007). Wood vinegar has been found to have a number of applications in the chemical, pharmaceutical and agricultural industries which include; (1) fungicides, pesticides and anti-germinating agents (Hagner, 2013), (2) used as repellent for; molluscs (Hagner, 2013), mosquitoes (KIARIE-MAKARA, YOON, \& LEE, 2010) and houseflies (Pangnakorn, Kanlaya, \& Kuntha, 2012). All the above studies attributed the vast applications of vinegar to the presence of acetic acid. During the present study, preliminary trials indicated that pine and eucalyptus wood vinegar and tar were lethal to black ants that are predominantly a menace to farmers in the Sub-Saharan Africa. The black ants were observed to die in about 2-5 minutes after exposure to the freshly prepared wood vinegar. Basing on the available data, it is not possible to conclude the optimal lethal concentration of either pine or eucalyptus wood vinegar for spraying black ants. However, it can be concluded that the pine and eucalyptus wood residues produce vinegar and tar through pyrolysis which are lethal to black ants. Also, the presence of oxygenated aliphatic and aromatic compounds promises the application of the organic products of pine and eucalyptus wood residues' pyrolysis in engine and transportation fuels (Lazzari et al., 2016; Yorgun \& Y1ld1z, 2015).

\subsection{The Energy Balance of the Pyrolysis Reactor System}

Table 4 shows the higher heating values of biomass, wood fuel, biochar, bio-oil, and the NCGs and their respective energy contents. For the products, biochar had the highest HHV $(28.53 \mathrm{MJ} / \mathrm{kg})$, followed by bio-oil $(27.2 \mathrm{MJ} / \mathrm{kg}$ ) and lastly NCGs $(3.22 \mathrm{MJ} / \mathrm{kg})$. There was no significant difference $(\mathrm{p}>0.05)$ between pine and eucalyptus HHV and therefore the average value was reported. Wood fuel had the highest energy content whereas NCGs had the lowest. The HHV for bio-oil obtained in the study was slightly lower than the values obtained in some studies such as (Ucar \& Ozkan, 2008) and (Yorgun \& Y1ld1z, 2015) but also higher than those obtained by others such as (Demirbas, 2007). According to Demirbas (2007), the HHV of the bio-oils is typically in the range of $15-20 \mathrm{MJ} / \mathrm{kg}$ which is only $40-50 \%$ of the conventional fossil fuels. The differences between the results of this study and some of the previous studies is due to the differences in the chemical composition and water content of both the feedstock and the produced bio-oil. The HHV of biochar fell in the range reported by (Demirbas, 2004) when he summarised the elemental composition of biochars from pyrolysis of several biomass feedstocks, at different heating rates and temperatures. The higher HHV makes chars attractive in some fuel applications as substitutes for coal (Ahmad et al., 2014). 
Table 4. Higher heating values and energy content for the feedstock and the products of the pyrolysis reactor system

\begin{tabular}{lll}
\hline Material & HHV $(\mathrm{MJ} / \mathrm{kg})$ & Energy content $(\mathrm{MJ})$ \\
\hline Biomass feedstock in the reactor & 19.79 & 79.16 \\
Biochar & 28.53 & 54.87 \\
Wood fuel & 25.20 & 101.38 \\
Bio-oil & 27.20 & 19.94 \\
NCG & 3.22 & 4.34 \\
\hline
\end{tabular}

The HHV for NCGs was relatively low as compared to other products. Several other researchers have obtained similar results and they attributed the low HHV of NCGs to high percentages of carbon dioxide (K.-H. Lee, Kang, Park, \& Kim, 2005; Luo et al., 2004; Piskorz et al., 1998). The typical LHVs of the pyrolytic gases range from 10 to $20 \mathrm{MJ} / \mathrm{Nm} 3$, depending on their practical composition (Kan et al., 2016). NCG had the lowest energy content due to its low calorific value whereas biochar had the highest due to its high calorific value and high yield. Although the NCGs had a relatively low energy content, they can provide some part of the energy requirements of the pyrolysis plant (Yanik et al., 2007). This can tremendously improve the efficiency of the pyrolysis process and system.

Table 5. Normalised energy values for the pyrolysis reactor input and output materials

\begin{tabular}{ll}
\hline Material & $\begin{array}{l}\text { Normalised energy content values (MJ/kg of biomass } \\
\text { pyrolysed) }\end{array}$ \\
\hline Wood fuel & 25.35 \\
Biomass feedstock & 19.79 \\
Biochar & 13.72 \\
Bio-oil & 4.99 \\
NCG & 1.09 \\
Total energy output (biochar + bio-oil +NCG) & 19.80 \\
Total input energy (wood fuel + biomass feedstock) & 45.14 \\
Input energy for the reactor system (wood fuel energy) & 25.35 \\
Input energy for the pyrolysis process (biomass & 19.79 \\
feedstock energy) & \\
The efficiency of the pyrolysis reactor system & 78.00 \\
\hline
\end{tabular}

Energy content values for all the materials involved in the energy balance calculations were normalised on per $\mathrm{kg}$ of biomass pyrolysed basis and the results are presented in Table 5. Total input and output energies of the reactor system per $\mathrm{kg}$ biomass pyrolysed are presented i.e. 45.14 and $19.8 \mathrm{MJ}$ respectively. 


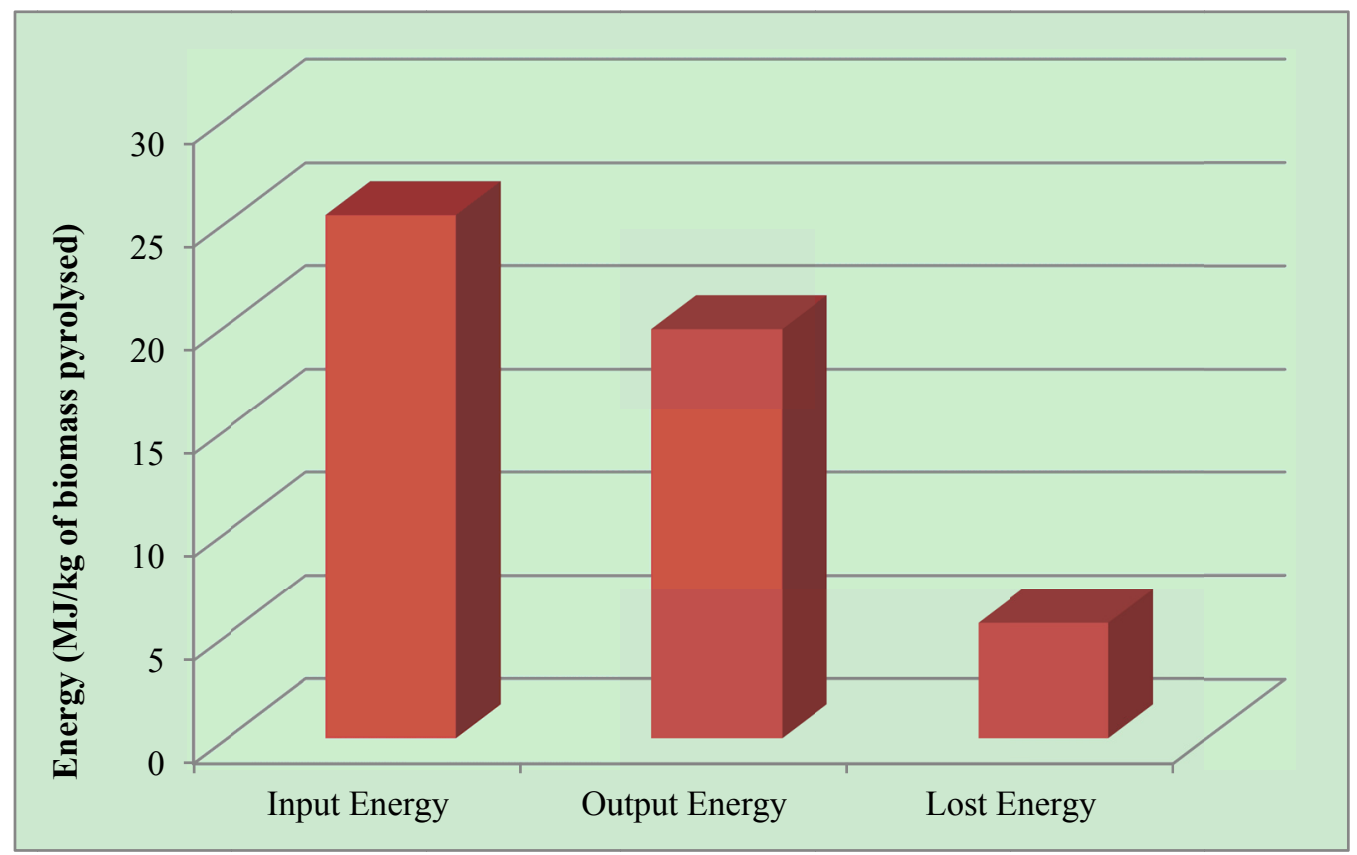

Figure 7. The energy balance of the pyrolysis reactor system per biomass feedstock pyrolysed

Figure 7 shows the energy balance of the reactor system with input, output and lost energy. The efficiency of the pyrolysis reactor system was found to be only $78 \%$ which implies that some energy is lost. This is a problem since the source of energy (wood fuel) for the reactor system is a scarce resource that needs to be used sparingly. However, the value attached to the bio-oils and biochar justifies why firewood can be used to produce these value-added products. The efficiency can be improved by recovering heat from the exhaust and using a better insulating material. Although this conversion happened successfully, NCGs were neither collected nor utilised in the system and hence can be considered as lost energy. Therefore, the system needs to be re-designed so as to incorporate recovery of the energy lost by venting the NCGs. The energy stored in the biomass was not considered as input energy when calculating pyrolysis reactor system efficiency because it wasn't the part of the sources of energy.

\section{Conclusions}

Pine and eucalyptus wood residues were pyrolysed in a cylindrical batch reactor and the organic products i.e. wood vinegar and tar were characterised. Wood vinegar and tar were mainly composed of acids, alcohols, ketones, furans and phenols and aldehydes. Acids were the most abundant compounds in the products with eucalyptus tar having the highest percentage (53.4\%) followed by pine-eucalyptus blend tar (42.0\%), eucalyptus vinegar $(33.8 \%)$, pine tar $(28.4 \%)$, and lastly pine vinegar (20.1\%). Eucalyptus vinegar and tar had higher percentages of acids, aldehydes, and furfurals whereas those of pine had higher ketones, alcohols, and phenols. Vinegar had higher concentrations of furfurals and aldehydes whereas tars had higher concentrations of acids and ketones. Tars contained no alcohols whereas vinegar contained no phenols. Pine and eucalyptus wood vinegar and tar are potential sources of engine fuels and chemicals such as organic pesticides, fungicides, and insecticides. Preliminary tests showed that pine and eucalyptus wood vinegar were lethal to black ants that are predominantly a menace to farmers in the tropics. Temperature strongly affected the yield and distribution of products. The yield of tar, vinegar, and biochar reduced with increasing temperature while that of non-condensable gases increased. The highest yield of biochar, vinegar, and tar was produced in the range $300-350^{\circ} \mathrm{C}$ whereas non-condensable gases were maximised in the $500-550^{\circ} \mathrm{C}$ range. The type of feedstock used (pine, eucalyptus or pine-eucalyptus blend) had no significant effect on the yield and distribution of products. Energy efficiency of the pyrolysis reactor system was $78 \%$.

\section{Acknowledgement}

This study was funded by the Regional Universities Forum for Capacity Development in Agriculture (RUFORUM) grant number (2015. RUGRG-2014-06-0010) and the University of Kentucky Appropriate Technology and Sustainability (UKATS) Research group. 


\section{References}

Ahmad, M., Rajapaksha, A. U., Lim, J. E., Zhang, M., Bolan, N., Mohan, D., . . Ok, Y. S. (2014). Biochar as a sorbent for contaminant management in soil and water: A review. Chemosphere, 99, 19-33. https://doi.org/10.1016/j.chemosphere.2013.10.071

Aiyeloja, A., Oladele, A., \& Furo, S. (2013). Sustaining livelihood through sawn wood marketing in Port Harcourt, Nigeria. Int. J. Sci. Nature, 4(1), 84-89.

Akhtar, J., \& Saidina Amin, N. (2012). A review on operating parameters for optimum liquid oil yield in biomass pyrolysis. Renewable and Sustainable Energy Reviews, 16(7), 5101-5109. https://doi.org/10.1016/j.rser.2012.05.033

Almeida, T. M., Bispo, M. D., Cardoso, A. R. T., Migliorini, M. V., Schena, T., de Campos, M. C. V., .. . Caramão, E. B. (2013). Preliminary Studies of Bio-oil from Fast Pyrolysis of Coconut Fibers. Journal of Agricultural and Food Chemistry, 61(28), 6812-6821.

Asadullah, M., Rahman, M. A., Ali, M. M., Rahman, M. S., Motin, M. A., Sultan, M. B., \& Alam, M. R. (2007). Production of bio-oil from fixed bed pyrolysis of bagasse. Fuel, 86(16), 2514-2520. https://doi.org/10.1016/j.fuel.2007.02.007

Ateş, F., \& Iş̧ıdağ, M. A. (2009). Influence of temperature and alumina catalyst on pyrolysis of corncob. Fuel, 88(10), 1991-1997. https://doi.org/10.1016/j.fuel.2009.03.008

Aysu, T., \& Küçük, M. M. (2014). Biomass pyrolysis in a fixed-bed reactor: Effects of pyrolysis parameters on product yields and characterisation of products. Energy, 64, 1002-1025. https://doi.org/10.1016/j.energy.2013.11.053

Bispo, M. D., Barros, J. A. S., Tomasini, D., Primaz, C., Caramao, E. B., Dariva, C., \& Krause, L. C. (2016). Pyrolysis of Agroindustrial Residues of Coffee, Sugarcane Straw and Coconut-Fibers in a Semi-pilot Plant for Production of Bio-oils: Gas Chromatographic Characterisation. J. Earth Sci. Eng, 6.

Boateng, A., Hicks, K., \& Vogel, K. P. (2006). Pyrolysis of switchgrass (Panicum virgatum) harvested at several stages of maturity. Journal of Analytical and Applied Pyrolysis, 75(2), 55-64.

Bridgwater, A. V. (2012). Review of fast pyrolysis of biomass and product upgrading. Biomass and bioenergy, $38,68-94$.

Cantrell, K. B., Hunt, P. G., Uchimiya, M., Novak, J. M., \& Ro, K. S. (2012). Impact of pyrolysis temperature and manure source on physicochemical characteristics of biochar. Bioresource technology, 107, 419-428. https://doi.org/10.1016/j.biortech.2011.11.084

Cao, J.-P., Xiao, X.-B., Zhang, S.-Y., Zhao, X.-Y., Sato, K., Ogawa, Y., . . Takarada, T. (2011). Preparation and characterisation of bio-oils from internally circulating fluidised-bed pyrolyses of municipal, livestock,

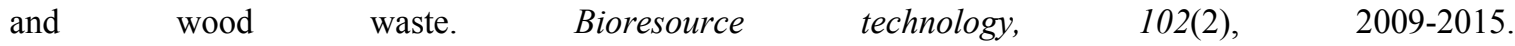
https://doi.org/10.1016/j.biortech.2010.09.057

Chen, B., Zhou, D., \& Zhu, L. (2008). Transitional Adsorption and Partition of Nonpolar and Polar Aromatic Contaminants by Biochars of Pine Needles with Different Pyrolytic Temperatures. Environmental Science \& Technology, 42(14), 5137-5143.

Chen, G., Andries, J., Luo, Z., \& Spliethoff, H. (2003). Biomass pyrolysis/gasification for product gas production: the overall investigation of parametric effects. Energy conversion and management, 44(11), 1875-1884. https://doi.org/10.1016/S0196-8904(02)00188-7

Choi, G.-G., Jung, S.-H., Oh, S.-J., \& Kim, J.-S. (2014). Total utilisation of waste tire rubber through pyrolysis to obtain oils and $\mathrm{CO} 2$ activation of pyrolysis char. Fuel Processing Technology, 123, 57-64. https://doi.org/10.1016/j.fuproc.2014.02.007

Cuiping, L., Chuangzhi, W., Yanyongjie, \& Haitao, H. (2004). Chemical elemental characteristics of biomass fuels in China. Biomass and bioenergy, 27(2), 119-130. https://doi.org/10.1016/j.biombioe.2004.01.002

Demiral, İ., \& Ayan, E. A. (2011). Pyrolysis of grape bagasse: Effect of pyrolysis conditions on the product yields and characterisation of the liquid product. Bioresource technology, 102(4), 3946-3951. https://doi.org/10.1016/j.biortech.2010.11.077 
Demirbas, A. (2004). Effects of temperature and particle size on biochar yield from pyrolysis of agricultural residues. Journal of Analytical and Applied Pyrolysis, 72(2), 243-248. https://doi.org/10.1016/j.jaap.2004.07.003

Demirbas, A. (2007). Progress and recent trends in biofuels. Progress in Energy and Combustion Science, 33(1), 1-18. https://doi.org/10.1016/j.pecs.2006.06.001

Demirbas, A. (2009). Progress and recent trends in biodiesel fuels. Energy conversion and management, 50(1), 14-34.

Faccini, C. S., Vecchia, I. D., Ribeiro, D., Zini, C. A., \& Caramão, E. B. (2013). Comprehensive 2D GC with TOF-MS detection: study of pyrolytic bio-oil of Kraft mill residues. Journal of the Brazilian Chemical Society, 24, 1085-1098.

Gerçel, H. F. (2011). Bio-oil production from Onopordum acanthium L. by slow pyrolysis. Journal of Analytical and Applied Pyrolysis, 92(1), 233-238. https://doi.org/10.1016/j.jaap.2011.06.002

González, J. F., Ramiro, A., González-García, C. M., Gañán, J., Encinar, J. M., Sabio, E., \& Rubiales, J. (2005). Pyrolysis of Almond Shells. Energy Applications of Fractions. Industrial \& Engineering Chemistry Research, 44(9), 3003-3012.

Hagner, M. (2013). Potential of the slow pyrolysis products birch tar oil, wood vinegar and biochar in sustainable plant protection: pesticidal effects, soil improvement and environmental risks.

Heidari, A., Stahl, R., Younesi, H., Rashidi, A., Troeger, N., \& Ghoreyshi, A. A. (2014). Effect of process conditions on product yield and composition of fast pyrolysis of Eucalyptus grandis in fluidised bed reactor. Journal of Industrial and Engineering Chemistry, 20(4), 2594-2602. https://doi.org/10.1016/j.jiec.2013.10.046

Jahirul, M., Rasul, M., Chowdhury, A., \& Ashwath, N. (2012). Biofuels production through biomass pyrolysis - a technological review. Energies, 5(12), 4952-5001.

Jeguirim, M., \& Trouvé, G. (2009). Pyrolysis characteristics and kinetics of Arundo donax using thermogravimetric analysis. Bioresource technology, 100(17), 4026-4031.: https://doi.org/10.1016/j.biortech.2009.03.033

Joshi, C., \& Seay, J. (2016). An appropriate technology based solution to convert waste plastic into fuel oil in underdeveloped regions. J. Sustain. Dev, 9(4), 133.

Kaboggoza, J. (2011). Forest plantations and woodlots in Uganda. African Forest.

Kan, T., Strezov, V., \& Evans, T. J. (2016). Lignocellulosic biomass pyrolysis: A review of product properties and effects of pyrolysis parameters. Renewable and Sustainable Energy Reviews, 57, 1126-1140. https://doi.org/10.1016/j.rser.2015.12.185

Keiluweit, M., Nico, P. S., Johnson, M. G., \& Kleber, M. (2010). Dynamic Molecular Structure of Plant Biomass-Derived Black Carbon (Biochar). Environmental Science \& Technology, 44(4), 1247-1253.

Kiarie-Makara, M. W., Yoon, H.-S., \& Lee, D.-K. (2010). Repellent efficacy of wood vinegar against Culex pipiens pallens and Aedes togoi (Diptera: Culicidae) under laboratory and semi-field conditions. Entomological Research, 40(2), 97-103.

Kloss, S., Zehetner, F., Dellantonio, A., Hamid, R., Ottner, F., Liedtke, V., . . Soja, G. (2012). Characterisation of Slow Pyrolysis Biochars: Effects of Feedstocks and Pyrolysis Temperature on Biochar Properties. Journal of Environmental Quality, 41, 990-1000.

Lazzari, E., Schena, T., Primaz, C. T., da Silva Maciel, G. P., Machado, M. E., Cardoso, C. A. L., . . Caramão, E. B. (2016). Production and chromatographic characterisation of bio-oil from the pyrolysis of mango seed waste. Industrial Crops and Products, 83, 529-536. https://doi.org/10.1016/j.indcrop.2015.12.073

Lee, K.-H., Kang, B.-S., Park, Y.-K., \& Kim, J.-S. (2005). Influence of Reaction Temperature, Pretreatment, and a Char Removal System on the Production of Bio-oil from Rice Straw by Fast Pyrolysis, Using a Fluidised Bed. Energy \& Fuels, 19(5), 2179-2184.

Lee, Y., Park, J., Ryu, C., Gang, K. S., Yang, W., Park, Y.-K., . . Hyun, S. (2013). Comparison of biochar properties from biomass residues produced by slow pyrolysis at $500^{\circ} \mathrm{C}$. Bioresource technology, 148 , 196-201. https://doi.org/10.1016/j.biortech.2013.08.135 
Liu, Z., Zhang, F.-S., \& Wu, J. (2010). Characterisation and application of chars produced from pinewood pyrolysis and hydrothermal treatment. Fuel, 89(2), 510-514. https://doi.org/10.1016/j.fuel.2009.08.042

Luo, Z., Wang, S., Liao, Y., Zhou, J., Gu, Y., \& Cen, K. (2004). Research on biomass fast pyrolysis for liquid fuel. Biomass and bioenergy, 26(5), 455-462. https://doi.org/10.1016/j.biombioe.2003.04.001

Marshall, A. S. J., Wu, P. F., Mun, S. H., \& Lalonde, C. (2014). Commercial application of pyrolysis technology in agriculture. Paper presented at the 2014 Montreal, Quebec Canada July 13-July 16, 2014.

Mohamed, B. A., Kim, C. S., Ellis, N., \& Bi, X. (2016). Microwave-assisted catalytic pyrolysis of switchgrass for improving bio-oil and biochar properties. Bioresource technology, 201, 121-132.

Mohan, D., Pittman, C. U., Bricka, M., Smith, F., Yancey, B., Mohammad, J., . . Gong, H. (2007). Sorption of arsenic, cadmium, and lead by chars produced from fast pyrolysis of wood and bark during bio-oil production. Journal of Colloid and Interface Science, 310(1), 57-73. https://doi.org/10.1016/j.jcis.2007.01.020

Mohan, D., Sarswat, A., Ok, Y. S., \& Pittman Jr, C. U. (2014). Organic and inorganic contaminants removal from water with biochar, a renewable, low cost and sustainable adsorbent-a critical review. Bioresource technology, 160, 191-202.

Moraes, M. S. A., Migliorini, M. V., Damasceno, F. C., Georges, F., Almeida, S., Zini, C. A., . . Caramão, E. B. (2012). Qualitative analysis of bio oils of agricultural residues obtained through pyrolysis using comprehensive two dimensional gas chromatography with time-of-flight mass spectrometric detector. Journal of Analytical and Applied Pyrolysis, 98, 51-64. https://doi.org/10.1016/j.jaap.2012.05.007

Mourant, D., Lievens, C., Gunawan, R., Wang, Y., Hu, X., Wu, L., . . Li, C.-Z. (2013). Effects of temperature on the yields and properties of bio-oil from the fast pyrolysis of mallee bark. Fuel, 108, 400-408.

Mullen, C. A., Boateng, A. A., Goldberg, N. M., Lima, I. M., Laird, D. A., \& Hicks, K. B. (2010). Bio-oil and biochar production from corn cobs and stover by fast pyrolysis. Biomass and bioenergy, 34(1), 67-74. https://doi.org/10.1016/j.biombioe.2009.09.012

Muradov, N., Fidalgo, B., Gujar, A. C., \& T-Raissi, A. (2010). Pyrolysis of fast-growing aquatic biomass Lemna minor (duckweed): Characterisation of pyrolysis products. Bioresource technology, 101(21), 8424-8428. https://doi.org/10.1016/j.biortech.2010.05.089

MWE. (2013). The National Forest Plan 2011/12-2021/22. Republic of Uganda. Retrieved from www.mwe.go.ug/

Ningbo, G., Baoling, L., Aimin, L., \& Juanjuan, L. (2015). Continuous pyrolysis of pine sawdust at different pyrolysis temperatures and solid residence times. Journal of Analytical and Applied Pyrolysis, 114, 155-162. https://doi.org/10.1016/j.jaap.2015.05.011

Obernberger, I., Brunner, T., \& Bärnthaler, G. (2006). Chemical properties of solid biofuels—significance and impact. Biomass and bioenergy, 30(11), 973-982. https://doi.org/10.1016/j.biombioe.2006.06.011

Ogunwusi, A. (2014). Wood waste generation in the forest industry in Nigeria and prospects for its industrial utilisation. Civil and Environmental Research, 6(9), 62-69.

Okello, C., Pindozzi, S., Faugno, S., \& Boccia, L. (2013). Bioenergy potential of agricultural and forest residues in Uganda. Biomass and bioenergy, 56, 515-525. https://doi.org/10.1016/j.biombioe.2013.06.003

Omulo, G., Willett, S., Seay, J., Banadda, N., Kabenge, I., Zziwa, A., . . SCARDA, R. (2017). Characterisation of slow pyrolysis wood vinegar and tar from banana wastes biomass as potential organic pesticides. Journal of Sustainable Development, 10(3), 81-92.

Önal, E. P., Uzun, B. B., \& Pütün, A. E. (2011). Steam pyrolysis of an industrial waste for bio-oil production. Fuel Processing Technology, 92(5), 879-885. https://doi.org/10.1016/j.fuproc.2010.12.006

Owoyemi, J. M., Zakariya, H. O., \& Elegbede, I. O. (2016). Sustainable wood waste management in Nigeria. Environmental \& Socio-economic Studies, 4(3), 1-9.

Pangnakorn, U., Kanlaya, S., \& Kuntha, C. (2012). Effect of Wood Vinegar for Controlling on Housefly (Musca domestica L.). International Journal of Agricultural and Biosystems Engineering, 6(5).

Paré, D., Bernier, P., Thiffault, E., \& Titus, B. D. (2011). The potential of forest biomass as an energy supply for Canada. The Forestry Chronicle, 87(1), 71-76. 
Park, H. J., Dong, J.-I., Jeon, J.-K., Park, Y.-K., Yoo, K.-S., Kim, S.-S., . . Kim, S. (2008). Effects of the operating parameters on the production of bio-oil in the fast pyrolysis of Japanese larch. Chemical Engineering Journal, 143(1), 124-132. https://doi.org/10.1016/j.cej.2007.12.031

Pattiya, A. (2011). Bio-oil production via fast pyrolysis of biomass residues from cassava plants in a $\begin{array}{lllll}\text { fluidised-bed } \quad \text { reactor. } & \text { Bioresource technology, } & 102(2), & \text { 1959-1967. }\end{array}$ https://doi.org/10.1016/j.biortech.2010.08.117

Pattiya, A., \& Suttibak, S. (2012). Production of bio-oil via fast pyrolysis of agricultural residues from cassava plantations in a fluidised-bed reactor with a hot vapour filtration unit. Journal of Analytical and Applied Pyrolysis, 95, 227-235. https://doi.org/10.1016/j.jaap.2012.02.010

Piskorz, J., Majerski, P., Radlein, D., Scott, D. S., \& Bridgwater, A. (1998). Fast pyrolysis of sweet sorghum and sweet sorghum bagasse. Journal of Analytical and Applied Pyrolysis, 46(1), 15-29.

Pütün, A. E., Önal, E., Uzun, B. B., \& Özbay, N. (2007). Comparison between the "slow" and "fast" pyrolysis of tobacco residue. Industrial Crops and Products, 26(3), 307-314.

Raveendran, K., \& Ganesh, A. (1996). Heating value of biomass and biomass pyrolysis products. Fuel, 75(15), $1715-1720$.

Rivilli, P. L., Alarcón, R., Isasmendi, G. L., \& Pérez, J. D. (2011). Stepwise isothermal fast pyrolysis (SIFP). Part II. SIFP of peanut shells-Antifungal properties of phenolic fractions. BioResources, 7(1), 0112-0117.

Sanna, A., Li, S., Linforth, R., Smart, K. A., \& Andrésen, J. M. (2011). Bio-oil and biochar from low temperature pyrolysis of spent grains using activated alumina. Bioresource technology, 102(22), 10695-10703.

Şensöz, S., Demiral, İ., \& Gerçel, H. F. (2006). Olive bagasse (Olea europea L.) pyrolysis. Bioresource technology, 97(3), 429-436.

Shafizadeh, F. (1982). Introduction to pyrolysis of biomass. Journal of Analytical and Applied Pyrolysis, 3(4), 283-305.

Shuangning, X., Weiming, Y., \& Li, B. (2005). Flash pyrolysis of agricultural residues using a plasma heated laminar entrained flow reactor. Biomass and bioenergy, 29(2), 135-141.

Sun, P., Heng, M., Sun, S.-H., \& Chen, J. (2011). Analysis of liquid and solid products from liquefaction of paulownia in hot-compressed water. Energy conversion and management, 52(2), 924-933.

Team, R. C. (2016). Austria Patent No.: R. F. f. S. Computing.

Theapparat, Y., Chandumpai, A., Leelasuphakul, W., \& Laemsuk, N. (2014). Physicochemical properties of pyroligneous acid from carbonisation of five wood species.

Tong, X.-j., Li, J.-y., Yuan, J.-h., \& Xu, R.-k. (2011). Adsorption of Cu (II) by biochars generated from three crop straws. Chemical Engineering Journal, 172(2-3), 828-834.

Tsai, W., Lee, M., \& Chang, Y. (2006). Fast pyrolysis of rice straw, sugarcane bagasse and coconut shell in an induction-heating reactor. Journal of Analytical and Applied Pyrolysis, 76(1-2), 230-237.

UBOS. (2015). Statistical Abstract. Republic of Uganda: Uganda Bureau of Standards. Retrieved from www.ubos.org/

Ucar, S., \& Ozkan, A. R. (2008). Characterisation of products from the pyrolysis of rapeseed oil cake. Bioresource technology, 99(18), 8771-8776.

Uzun, B. B., \& Sarioğlu, N. (2009). Rapid and catalytic pyrolysis of corn stalks. Fuel Processing Technology, 90(5), 705-716.

Vispute, T. P., \& Huber, G. W. (2009). Production of hydrogen, alkanes and polyols by aqueous phase processing of wood-derived pyrolysis oils. Green Chemistry, 11(9), 1433-1445.

Wang, S., Guo, X., Wang, K., \& Luo, Z. (2011). Influence of the interaction of components on the pyrolysis behavior of biomass. Journal of Analytical and Applied Pyrolysis, 91(1), 183-189.

Wei, L., Xu, S., Zhang, L., Zhang, H., Liu, C., Zhu, H., \& Liu, S. (2006). Characteristics of fast pyrolysis of biomass in a free fall reactor. Fuel Processing Technology, 87(10), 863-871.

Wu, Q., Zhang, S., Hou, B., Zheng, H., Deng, W., Liu, D., \& Tang, W. (2015). Study on the preparation of wood vinegar from biomass residues by carbonisation process. Bioresource technology, 179, 98-103. 
WWF. (2012). A report on National Timber Trade and FLEGT Solutions for Uganda. Kampala, Uganda: WWF-World Wide Fund for Nature (Formerly World Wildlife Fund).

Xiu, S., \& Shahbazi, A. (2012). Bio-oil production and upgrading research: A review. Renewable and Sustainable Energy Reviews, 16(7), 4406-4414.

Yanik, J., Kornmayer, C., Saglam, M., \& Yüksel, M. (2007). Fast pyrolysis of agricultural wastes: Characterisation of pyrolysis products. Fuel Processing Technology, 88(10), 942-947.

Yorgun, S., \& Y1ld1z, D. (2015). Slow pyrolysis of paulownia wood: Effects of pyrolysis parameters on product yields and bio-oil characterisation. Journal of Analytical and Applied Pyrolysis, 114, 68-78.

Zheng, J.-L. (2008). Pyrolysis oil from fast pyrolysis of maize stalk. Journal of Analytical and Applied Pyrolysis, $83(2), 205-212$.

\section{Copyrights}

Copyright for this article is retained by the author(s), with first publication rights granted to the journal.

This is an open-access article distributed under the terms and conditions of the Creative Commons Attribution license (http://creativecommons.org/licenses/by/4.0/). 